\title{
CloudSat observations of cloud-type distribution over the Indian summer monsoon region
}

\author{
K. V. Subrahmanyam and K. K. Kumar \\ Space Physics Laboratory, Vikram Sarabhai Space Centre, Thiruvananthapuram, Kerala, India \\ Correspondence to: K. K. Kumar (kishore_nmrf@yahoo.com)
}

Received: 26 February 2013 - Revised: 22 May 2013 - Accepted: 24 May 2013 - Published: 3 July 2013

\begin{abstract}
The three-dimensional distribution of various cloud types over the Indian summer monsoon (ISM) region using five years (2006-2010) of CloudSat observations during June-July-August-September months is discussed for the first time. As the radiative properties, latent heat released and microphysical properties of clouds differ largely depending on the cloud type, it becomes important to know what types of clouds occur over which region. In this regard, the present analysis establishes the three-dimensional distribution of frequency of occurrence of stratus (St), stratocumulus $(\mathrm{Sc})$, nimbostratus ( $\mathrm{Ns})$, cumulus $(\mathrm{Cu})$, altocumulus $(\mathrm{Ac})$, altostratus (As), cirrus (Ci) and deep convective (DC) clouds over the ISM region. The results show that the various cloud types preferentially occur over some regions of the ISM, which are consistent during all the years of observations. It is found that the DC clouds frequently occur over northeast of Bay of Bengal (BoB), $\mathrm{Ci}$ clouds over a wide region of south BoB-Indian peninsula-equatorial Indian Ocean, and Sc clouds over the north Arabian Sea. Ac clouds preferentially occur over land, and a large amount of As clouds are found over BoB. The occurrence of both St and Ns clouds over the study region is much lower than all other cloud types. The interannual variability of all these clouds including their vertical distribution is discussed. It is envisaged that the present study opens up possibilities to quantify the feedback of individual cloud type in the maintenance of the ISM through radiative forcing and latent heat release.
\end{abstract}

Keywords. Meteorology and atmospheric dynamics (tropical meteorology)

\section{Introduction}

Owing to its socioeconomic impacts, the Indian summer monsoon (ISM) is one of the most investigated topics in the realms of meteorology. Many studies on the ISM by several researchers across the globe contributed constructively to the present understanding of this enigmatic large-scale system (Webster et al., 1998; Gadgil, 2003). Generally, it is believed that the continental-scale land-sea thermal contrast is the origin of large-scale monsoon circulation (Wallace and Hobbs, 1977). However, once the monsoon is set, its advancement, maintenance and withdrawal depends not only on the largescale dynamics but also on the internal dynamics initiated by the cloud systems embedded within the monsoon system. These cloud systems over the ISM region modify the thermal structure and moisture budget of the troposphere by releasing latent heat, modifying the radiative heat, and through precipitation. Thus the clouds are an important integral part of the monsoon system, and any attempt to understand the latter should include the detailed investigations on the former. Realizing its importance, many attempts were made in the past to study the cloud distribution over the ISM region (Grossman and Garcia, 1990; Laing and Fritch, 1993). Most of these studies used passive remote sensing techniques and are thus limited to fraction of cloud cover over the ISM region. However, Wonsick et al. (2009) focused on detailed study on cloud variability over the monsoon region in terms of total, low, high and convective cloud amounts throughout the different phases of the monsoon. Very recently, Li et al. (2011) accessed the radiative impacts of single- and multi-layered clouds using A-Train observations. These results indicated that the multi-layer clouds have a significant impact on radiation budget and differ with that of single-layered clouds. Thus it is important to know not only the amount of cloud 
cover but also its vertical distribution. For example, highlevel clouds tend to warm the climate, while low-level clouds lead to a cooling effect (Ramananthan et al., 1989). Recently, Tang and Chen (2006), using the MODIS/Terra measured cloud properties dataset, investigated the characteristics of clouds associated with the Asian summer monsoon. These authors emphasized the distribution of low-, mid- and highlevel clouds and found that a large amount of high clouds exist in the Indian monsoon region. Thus it becomes important to know the three-dimensional distribution of the clouds.

Apart from the total cloud amount and its vertical distribution, one more important aspect of clouds is the cloud type. It is known that depending upon the cloud type, the radiative properties, the latent heat released and microphysical properties of clouds largely differ. Chen et al. (2000) investigated the radiative flux changes induced by the occurrence of different cloud types using International Satellite Cloud Climatology Project cloud data and a radiative transfer model. These authors emphatically showed that the cloud-type variations are as important as cloud cover in modifying the radiation field of the earth-atmosphere system and further showed that the largest annual mean changes of the global top-of-atmosphere and surface shortwave radiative fluxes are produced by stratocumulus, altostratus, and cirrostratus clouds; whereas cirrus, cirrostratus, and deep convective clouds cause most of the annual mean changes in the global top-of atmosphere longwave radiative fluxes. Thus it becomes clear that, apart from the three-dimensional distribution of cloud cover, it is important to have cloud type distribution to quantify the feedback provided by the clouds in totality.

Even though there are studies on cloud distribution over the ISM region, there are no studies focusing on cloud type distribution. Sufficient knowledge of the spatial distribution of individual cloud types would aid the accurate radiation and latent heat calculations, which in turn would help in accessing the role of clouds in the maintenance and advancement of the ISM. So it becomes important to know which types of clouds occur over which region. In this regard, a study is carried out using five years (2006-2010) of CloudSat observations during June-July-August-September (JJAS) months to establish the three-dimensional distribution of individual cloud types over the ISM region for the first time. Section 2 provides the data and methodology. Results are discussed in Sect. 3, and Sect. 4 provides the summary.

\section{Data and methodology}

Five years of CloudSat observations during June-JulyAugust-September months over the ISM region form the basis for the present study. The cloud profiling radar (CPR) onboard CloudSat operates at $94 \mathrm{GHz}$ with cross- and alongtrack resolution of 1.4 and $1.7 \mathrm{~km}$ respectively, which is a part of the A-Train constellation. With $\sim 240 \mathrm{~m}$ vertical res- olution, CPR can probe optically thick large-particle layers. However, CPR is not sensitive to optically thin clouds such as high-altitude cirrus clouds. More details on CloudSat can be found in Stephens et al. (2008). For the present study, we use the 2B-CLDCLASS data product of version 5 over the ISM region $\left(10^{\circ} \mathrm{S}\right.$ to $30^{\circ} \mathrm{N}, 50^{\circ}$ to $\left.100^{\circ} \mathrm{E}\right)$. In the following section, we briefly discuss the cloud classification algorithm, which was implemented in deriving the 2BCLDCLASS product.

Wang and Sassen (2001) developed an algorithm to classify clouds by combining the measurements of ground-based multiple remote sensors. Further, Sassen and Wang (2008) described the cloud cluster analysis for classifying clouds by using vertical and horizontal cloud properties, the presence or absence of precipitation from both CloudSat and MODIS observations along with ECMWF temperature profiles. The present data product uses this algorithm for cloud type classification. The cloud cluster analysis converts the vertical profiles of reflectivity from CloudSat into meaningful microphysical data quantities and identifies the clouds based on the cloud mask algorithm. The cloud clustering analysis provides cloud horizontal and vertical extent features and cloud layer structure with significant CPR cloud mask values $(\geq 30)$. Further, classification of the cloud type is done based on microphysical properties, maximum reflectivity and corresponding temperature at that level, cloud vertical and horizontal extent and the precipitating properties. Complete details on the cloud classification algorithm can be found in the 2B-CLDCLASS product description document at http: //www.cloudsat.cira.colostate.edu/dataHome.php. The maximum number of cloud types provided by this product is eight: cirrus (Ci), altostratus (As), altocumulus (Ac), stratus $(\mathrm{St})$, stratocumulus $(\mathrm{Sc})$, cumulus $(\mathrm{Cu})$, nimbostratus $(\mathrm{Ns})$ and deep convective (DC) clouds (i.e., cumulonimbus). Out of the eight clouds, Ns, St, Sc, Cu, Ac and Dc are categorized as precipitating clouds, and remaining clouds are nonprecipitating clouds. Further these clouds are classified into high-, middle- and low-level clouds. This product is available as a function of latitude, longitude and altitude with the same resolution as that of CPR. There have been attempts in the recent past to validate this product. The CloudSat Educational Network (CEN), a primary education and public outreach component of the CloudSat mission, collected visual observations of cloud type during the period of 20072008 and compared the observed cloud types to those retrieved using the CloudSat 2B-CLDCLASS product. There were 227 coincidental measurements of CEN and CloudSat within $\sim 100 \mathrm{~km}$ radius. The preliminary comparison has shown $66 \%$ agreement between the surface observers and CloudSat observations (Rogers and Vane, 2010). Very recently, Behrangi et al. (2012) used the 2B-CLDCLASS product to study the vertical and horizontal distributions of the cloud types across different seasons over the contiguous USA and surrounding areas. In this study, the authors describe the 2B-CLDCLASS product in detail including their limitations: 

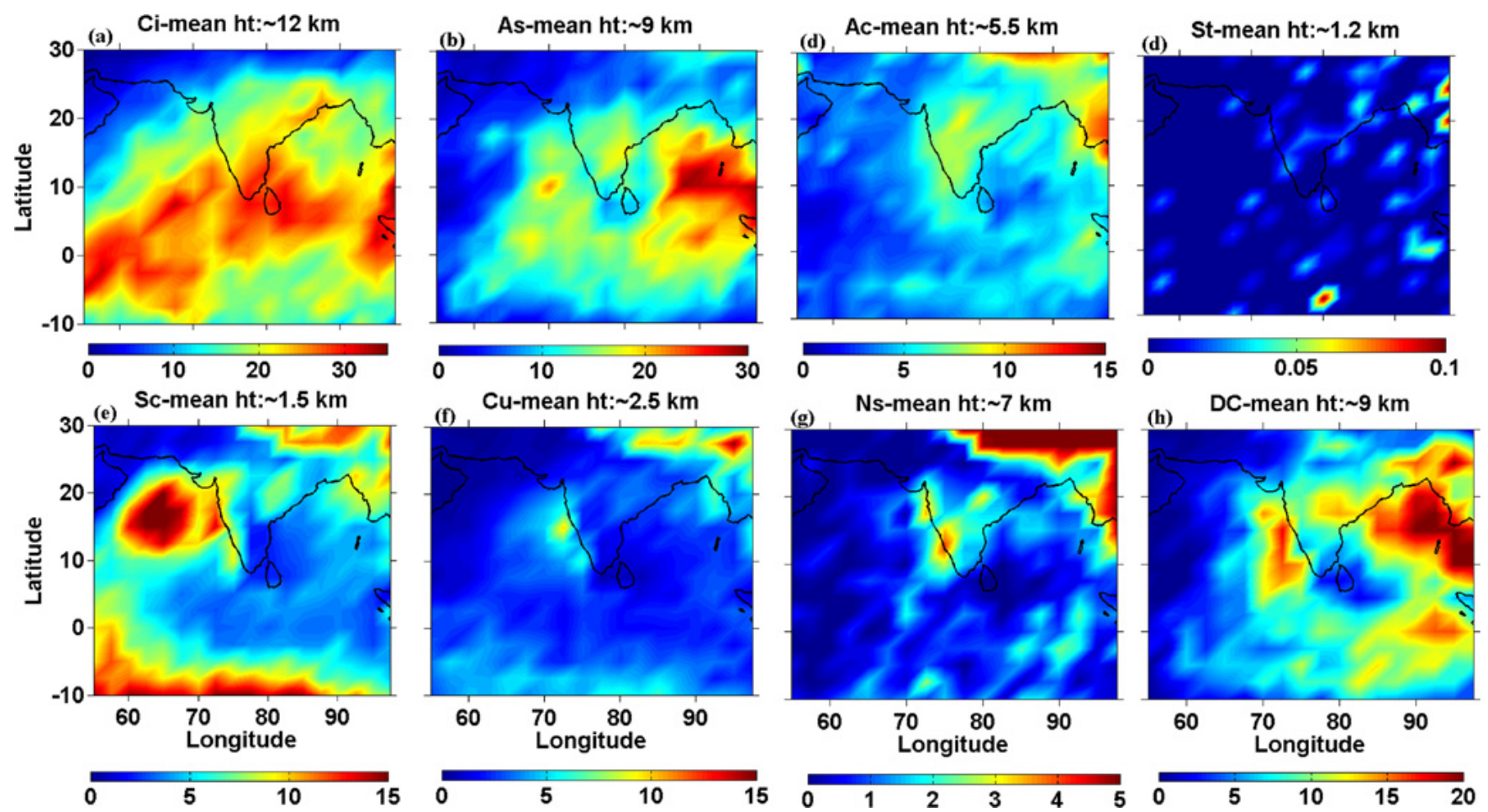

Fig. 1. Five-year (2006-2010) mean distribution of frequency of occurrence during JJAS of (a) Ci, (b) As, (c) Ac, (d) St, (e) Sc, (f) Cu, (g) Ns and (h) DC clouds over the ISM region. Both day- and nighttime observations of CloudSat are used for the analysis. The mean altitude provided at the top of the maps corresponds to the average of peak altitudes at which maximum frequency of occurrence is observed over the study region (see text for more details).

(1) surface contaminations in the lower 3 to 4 range bins of CPR vertical reflectivity profiles will have implications in classifying St and Sc clouds, and (2) the CPR is not sensitive to high-altitude thin clouds, which will have implications in detecting the $\mathrm{Ci}$ clouds. Thus both these limitations will result in fewer detections of $\mathrm{St}, \mathrm{Sc}$ and $\mathrm{Ci}$ clouds than actually present. One should keep these things in mind while interpreting the observations. The second limitation can be overcome by combining the CALIPSO observations. However, it will be done in near future.

We have followed the following procedure to calculate the frequency of occurrence of each cloud type. (1) The observations over the study region are grouped into $2.5 \times 2.5$ grid boxes. (2) The number of occurrences of each cloud type as a function of altitude is estimated in each grid box. (3) The number of occurrences of each cloud type is then divided by the number of occurrences of all cloud types at each altitude. (4) Step 3 yielded the height profile of frequency of occurrence of each cloud type within each grid box. (5) From these height profiles, the altitude at which the maximum frequency of occurrence takes place is found for each cloud type for a given grid box. (6) The maximum frequency of occurrence at the altitude (provided by step 5) is then used to create the maps over the ISM region, which will be discussed in the next section. The height profiles of frequency of occurrence in each grid box provided the 3-D distribution of cloud types over the ISM region.

\section{Results and discussion}

By adopting the method described in Sect. 2, we quantified the frequency of occurrence of various cloud types, and Fig. 1a-h show the five-year (2006-2010) mean distribution of frequency of occurrence of $\mathrm{Ci}, \mathrm{As}, \mathrm{Ac}, \mathrm{St}, \mathrm{Sc}, \mathrm{Cu}, \mathrm{Ns}$ and DC clouds over the ISM region during JJAS. Figure 1 contains both daytime and nighttime observations of CloudSat. It has to be remembered that we have estimated the frequency of occurrence at each altitude bin and Fig. 1 corresponds to the altitude where maximum frequency of occurrence of corresponding cloud is observed. As the altitude at which maximum frequency of occurrence takes place differs from one grid box to another, we have taken the mean of these altitudes over the study region, and the same is provided in Fig. 1 as mean altitude. From Fig. 1a it is evident that the distribution of $\mathrm{Ci}$ is highly concentrated over south Bay of Bengal (BoB), Indian peninsula and Indian Ocean. During the ISM, the convective storms over most northern parts of $\mathrm{BoB}$ (known as head $\mathrm{BoB}$ ) produce copious amounts of $\mathrm{Ci}$ clouds (formed from the anvil of deep convective clouds), which are spread over the ISM region by the strong Tropical Easterly Jet (TEJ) 
(Sathiyamoorthy et al., 2004). The maximum percentage of occurrence of Ci cloud is $\sim 30-35 \%$. As discussed in Sect. 2 , the CloudSat underestimates the occurrence of $\mathrm{Ci}$ clouds as it is not sensitive to optically thin cirrus clouds. CloudSat observations over the ISM region are limited to two local times per day. If there are any diurnal variations in particular cloud occurrence, it may bias the frequency of occurrence estimations discussed here (however, an attempt is made to bring out the differences between the frequencies of occurrence of each cloud during day- and nighttime over the ISM region, which will be discussed later in this section). The $\mathrm{Ci}$ clouds are known for their role in radiative forcing, and thus their unambiguous spatial distribution assumes its importance. Figure $1 \mathrm{~b}$ shows the distribution of frequency of occurrence of As clouds, which seem to occur preferentially over BoB compared to over the Arabian Sea. Interestingly, occurrence frequency of As cloud is higher over oceans than over land in contrast to Ac cloud distribution shown in Fig. 1c, which frequently occur over land. The frequency of occurrence of Ac is found to be high over Bangladesh, Tibetan Plateau region and uniformly distributed over the Indian landmass. The preferential occurrence of Ac over land is a relatively new observation and needs to be further investigated in terms of microphysical processes associated with Ac clouds. Frequency of occurrence of St and Ns clouds is shown in Fig. 1e and g, respectively. From these maps it is evident that occurrence of these two clouds is very low compared to other cloud types over the study region. Especially the occurrence of St clouds is almost non-existent over the ISM region. This can be to some extent attributed to the surface contamination of CPR in the lower heights up to $\sim 1 \mathrm{~km}$. But, in the case of Ns cloud distribution, there is considerable amount of occurrences over the Tibetan Plateau region.

Frequency of occurrence of Sc cloud is shown in Fig. 1e, which readily reveals its maximum occurrence over the Arabian Sea region and also over equatorial Indian Ocean. It is interesting to note that the Sc clouds form scarcely over the BoB. The spatial distribution of Sc clouds is also very crucial as it plays an important role in shortwave radiative forcing resulting in cooling of the surface. The confinement of Sc clouds over the Arabian Sea can be attributed to the descending motion from monsoon convection apart from lower tropospheric thermal inversion that occurs during the ISM period over this region (Sathiyamoorthy et al., 2011). The weak descending motions over the Arabian Sea during the ISM period can suppress the vertical development of clouds. The strong winds over the Arabian Sea during the ISM period can cool the sea surface by upwelling, which also can play a role in suppressing the convection. Besides these reasons, there is a strong mixing of dry air from Arabian Desert at around 650-500 hpa (figure not shown), which further dilutes the vertical development of the convection over the Arabian Sea. Thus there are strong dynamical processes that prevail over the Arabian Sea, which results in limiting the convec- tion growth and seems to be the prime reason for formation of Sc clouds as observed in the present study.

Figure $1 \mathrm{f}$ shows the frequency of occurrence of $\mathrm{Cu}$ clouds, which are relatively high over Tibetan Plateau region and the western coast of southern India. A secondary peak can also be observed in $\mathrm{Cu}$ occurrence over equatorial Indian Ocean. Other than these regions, $\mathrm{Cu}$ occurrence frequency is very low over the study region. The distribution of DC clouds, which are very important in both radiative and latent heat estimations as well as in precipitation over the ISM region, is shown in Fig. 1h. Compared to other cloud types, the distribution of DC clouds has been well documented over the ISM region (Grossman and Garcia, 1990; Laing and Fritsch, 1993; Houze et al., 2007). From Fig. 1h, it can be noted that the DC clouds are highly concentrated in the northeast of $\mathrm{BoB}$, a consistent feature reported by earlier studies (Zuidema, 2003). A secondary peak in frequency of occurrence of DC can be noted over the western coast of India and central India. These DC clouds produce large amounts of precipitation, and good or bad monsoon mostly depends on the distribution and frequency of occurrence of these clouds. It is also known that the highest mean precipitation over the ISM region takes place over BoB, and thus the distribution of DC clouds becomes very important not only from a hydrological standpoint but also from a dynamical standpoint as large amounts of latent heat released in these system maintain the monsoon circulation (Zuidema, 2003). The continental tropical convergence zone, which extends from the Indo-Gangetic Plain into the BoB, plays a key role in the development of DC clouds by pumping the sufficient moisture into the atmosphere over the north BoB. Thus Fig. 1a-h depict the five-year mean distribution of various cloud types associated with the ISM, and it is observed that dynamics plays a vital role in this distribution. As mentioned earlier, it is important to know what type of cloud forms over which region to assess the feedback provided by the clouds to the large-scale ISM. Figure 1 provides these details for the first time.

It is important to know the diurnal variation in occurrence of cloud types, if any, as CloudSat observations cover only two local times over the ISM region. These satellites cross the Equator at approximately 13:30 and 01:30 local times. Over the ISM region CloudSat observations are made at $\sim$ 06:00-09:00 UTC (local day) and 18:00-21:00 UTC (local night). The results depicted in Fig. 1 correspond to the mean of all the observations regardless of day or night. As the observations from CloudSat are available during both day and night, an attempt is made to evaluate the difference between the day and night distribution of frequency of occurrence of various cloud types, and the same is shown in Fig. 2. We have generated the distribution maps similar to Fig. 1 for both day- and nighttime separately. The nighttime maps are then subtracted from the daytime maps to obtain the difference between the two. The positive values in Fig. 2 indicate that the particular cloud type occurrence is higher during the daytime than during the nighttime. The first impression from 

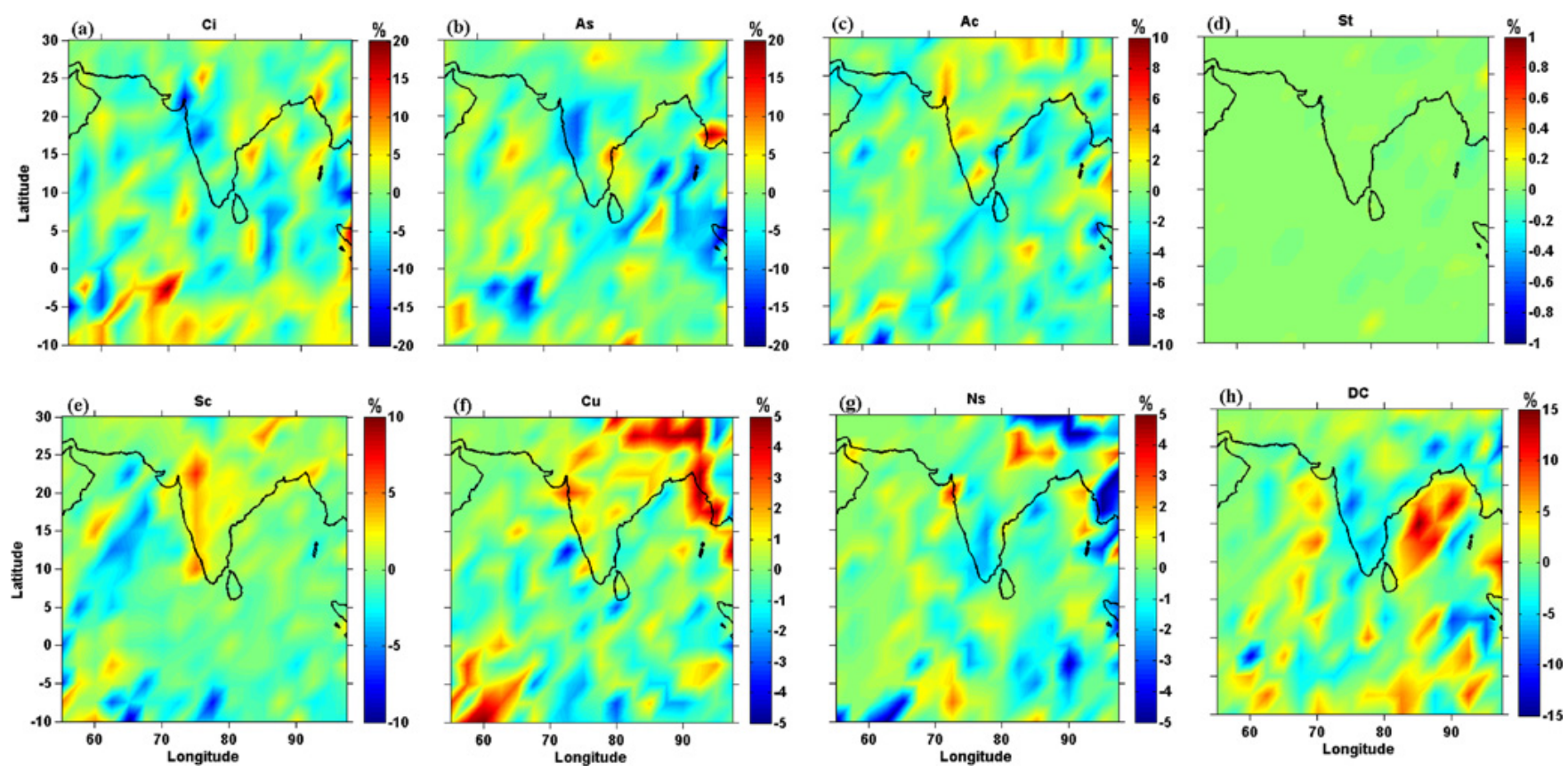

Fig. 2. Same as Fig. 1 but for differences in frequency of occurrence during day- and nighttime.

this figure is that there is no coherent diurnal variation in occurrence of various cloud type except for DC clouds over $\mathrm{BoB}$. Again, the St cloud is underrepresented here. Most of the clouds show a diurnal variation of $\sim 5 \%$ in their occurrence. However, there are pockets of isolated highs in diurnal variations as in the case of $\mathrm{Ci}$ clouds over the Indian Ocean, which show diurnal variation as high as $20 \%$. The DC clouds show $\sim 15 \%$ diurnal variations especially over BoB. With these few exceptions, there is no notable diurnal variation in the occurrence of particular cloud types over the ISM region. Thus the five-year JJAS mean distribution of frequency of occurrence of cloud types shown in Fig. 1 is not much affected by the diurnal variations in cloud occurrence frequency as CloudSat observations are available during both local dayand nighttime as confirmed from Fig. 2.

One of the most complex problems associated with the ISM is its interannual variability (Goswami and Xavier, 2005). A part of the interannual variability of the ISM can be attributed to the interannual variability of the various cloud distribution and the feedback provided by these clouds. In order to investigate the interannual variability of the frequency of occurrence of various cloud types, we have established the same for individual years from 2006 to 2010 . Figure $3 a-f$ show the interannual variations in frequency of occurrence of the various cloud types $\mathrm{Ci}, \mathrm{As}, \mathrm{Ac}, \mathrm{Sc}, \mathrm{Cu}$ and $\mathrm{DC}$ clouds respectively from 2006 to 2010 . The interannual variability of St and Ns is not included here as their frequency of occurrence is lower than other cloud types, as mentioned earlier. The frequency of occurrence of $\mathrm{Ci}$ clouds is relatively higher over the south Arabian Sea and equatorial Indian Ocean in
2006, 2007 and 2010, whereas the distribution of $\mathrm{Ci}$ is higher over south BoB in 2008 and 2009. However, during all the years, one can notice the signature of TEJ in the distribution of $\mathrm{Ci}$ clouds. Further, the distribution of $\mathrm{Ci}$ clouds depends on the distribution of DC clouds over head $\mathrm{BoB}$, as a majority of Ci clouds over the ISM are formed from the outflow of DC clouds. The interannual variation of As clouds is shown in Fig. 3b, which readily reveals that the distribution of these clouds is limited to BoB during the years 2006, 2008 and 2009, whereas it is observed over the Arabian Sea also during the years 2007 and 2010. With an exception during the year 2009, the distribution of As over the Arabian Sea seems to exhibit the biennial oscillation. Figure $3 \mathrm{c}$ depicts the interannual variation of Ac clouds; as discussed earlier, these clouds preferentially form over land. There is a little interannual variation in the Ac cloud distribution over the ISM region. The interannual variation of Sc clouds is shown in Fig. 3d. It is very interesting to note the consistency of these cloud occurrences over the Arabian Sea as well as over the equatorial Indian Ocean during all the years. Except during the 2009, the frequency of occurrence of these clouds over the Arabian Sea is coherent and limited to a narrow region, and the interannual variation is not very prominent. Figure $3 \mathrm{e}$ shows the interannual variation of $\mathrm{Cu}$ clouds. There are two prominent peaks in the occurrence of these clouds: one over the Tibetan Plateau and the other over the west coast of India. There is a little interannual variation in their occurrence over these regions. Finally, the interannual variation of DC cloud occurrence is shown in Fig. 3f. From this figure, it is evident that the DC clouds spread over the entire BoB and 

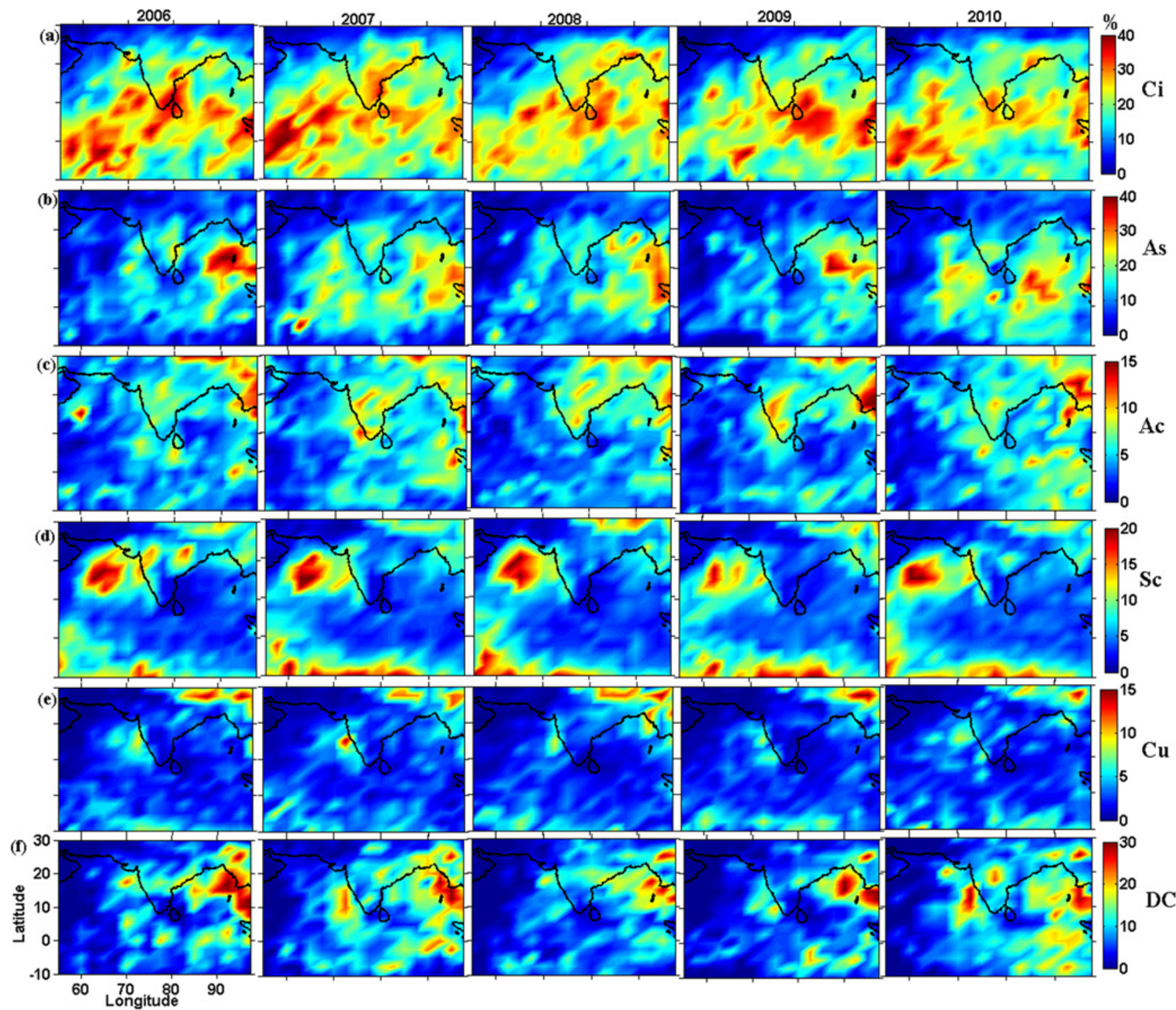

Fig. 3. Distribution of frequency of occurrence of (a) Ci, (b) As, (c) Ac, (d) Sc, (e) Cu and (f) DC clouds during the years 2006-2010.

the Arabian Sea region in 2007 and 2010, whereas in 2006, 2008 and 2009 they are highly concentrated in the northeast BoB. One more noteworthy observation is the lack of DC clouds over the Indian landmass during the year 2009 as compared to other years. The year 2009 was a drought year with $22 \%$ deficiency in all India monsoon rainfall as compared to the long-term monsoon rainfall over the region. Thus Fig. 3a-f describe the interannual variation in distribution of frequency of various cloud types occurring over the ISM region. The dynamical, thermal and moisture structure of the background atmosphere during these years could be the principal reason for the observed interannual variability of these clouds, which have to be further investigated.

As mentioned earlier, the distributions shown in Figs. 1 and 3 correspond to the height at which maximum occur- rence of that particular cloud is found. However, it will be useful to have the height distribution of various cloud types over the ISM region. In this regard, we have averaged the frequency of occurrence of individual cloud types in each range bin over the entire ISM region, and Fig. $4 \mathrm{a}-\mathrm{f}$ show the vertical distribution of frequency of occurrence of $\mathrm{Ci}$, As, Ac, Sc, $\mathrm{Cu}$ and DC clouds, respectively. The vertical distribution of $\mathrm{Ci}, \mathrm{As}, \mathrm{Ac}, \mathrm{Sc}, \mathrm{Cu}$ and $\mathrm{DC}$ clouds peaks at 12, 7.5, 6, 1.1, 2 and $5 \mathrm{~km}$ height, respectively. The deviations of all India monsoon rainfall from the long-term mean during the individual years 2006-2010 are given in Fig. 4f. This information has been taken from the India Meteorological Department. From these rainfall deviations, it can be noted that the year 2009 is a drought, and all other years are near-normal (2006 and 2008) to excess years (2007 and 2010). During 

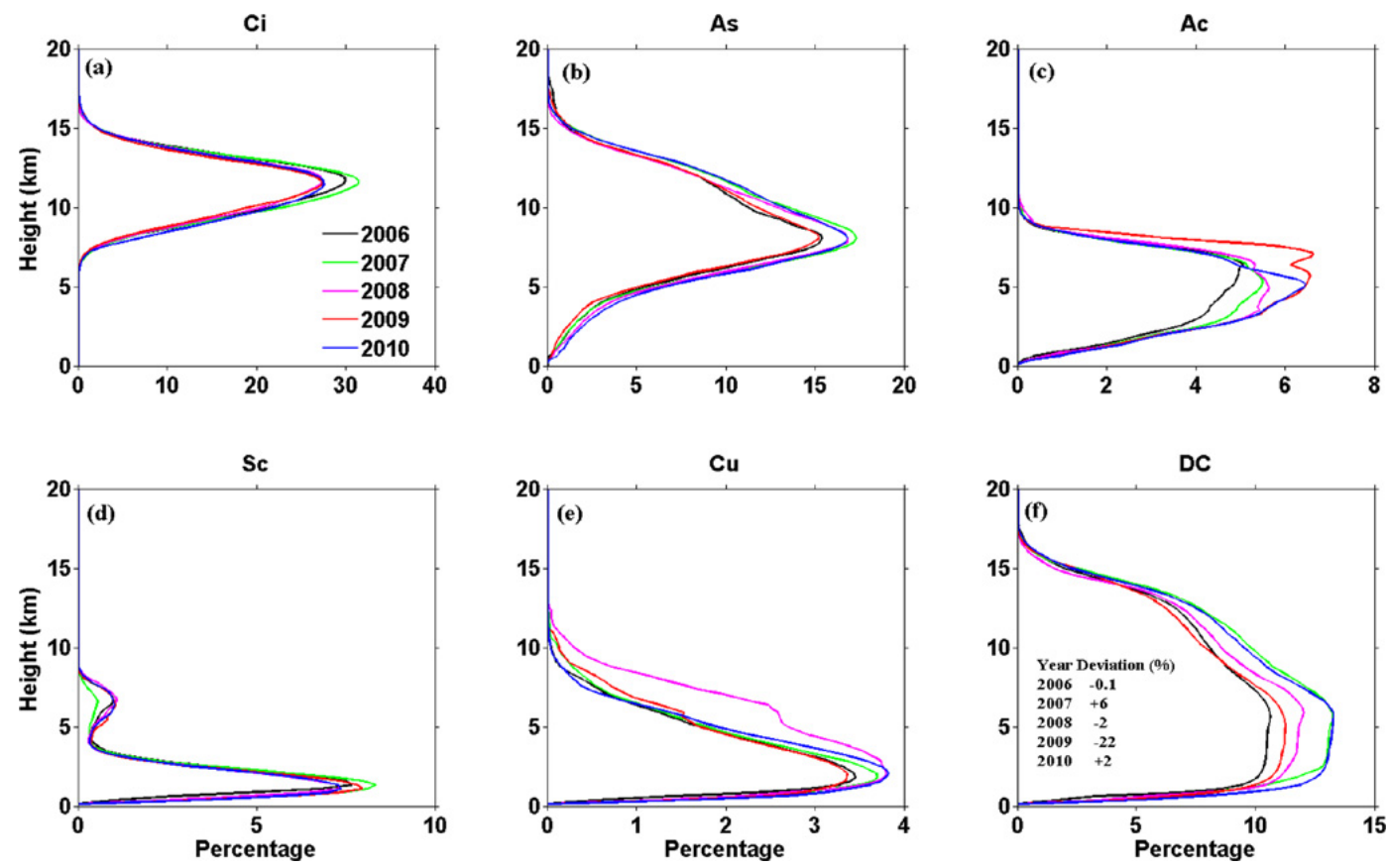

Fig. 4. Vertical distribution of frequency of occurrence of (a) Ci, (b) As, (c) Ac, (d) St, (e) Cu and (f) DC clouds averaged over the ISM region during 2006-2010.

the drought year of 2009, it can be noticed that the frequencies of occurrence of all cloud types are reduced compared to other years, and it is very interesting to note that the vertical distribution of DC clouds reflects the monsoon rainfall (i.e., their frequency of occurrence is higher in excess years than in near-normal and drought years). Thus the present study established the three-dimensional distribution of various cloud types occurring over the ISM region for the first time, which are very vital for understanding the feedback provided by the clouds to the monsoon system. The present study also opens up the possibility to assess the role of individual cloud types in modifying the background thermal structure of the troposphere through radiative and latent heat.

\section{Conclusions}

Five years (2006-2010) of CloudSat observations over the ISM region are used to establish the three-dimensional distribution of various cloud types in terms of their frequency of occurrence for the first time. The mean distribution of Ci clouds emphatically showed the role of TEJ in spreading the anvils of DC clouds forming over the head BoB. These clouds are most frequently observed over the Indian peninsula, south BoB and Indian Ocean. It is observed that the Sc clouds form most frequently over the north Arabian Sea and are confined to a narrow region. The prevailing dynamical features during the ISM period seem to be responsible for the formation of these clouds over the Arabian Sea. It is also observed that Ac clouds form preferentially over land and As clouds over BoB. The mean distribution of $\mathrm{Cu}$ clouds showed three distinct peaks over the Tibetan Plateau, western coast and equatorial Indian Ocean. The distribution of DC clouds, which are very important from a hydrological standpoint, showed a pronounced peak in their occurrence frequency over head BoB and secondary peaks over western coast, south BoB and central India. The frequencies of occurrence of St and Ns clouds are found to be much lower than other cloud types over study region. The diurnal variations in frequency of occurrence of all these clouds are also established using day- and nighttime observations of CloudSat. The interannual variations of all these clouds are discussed, and it is observed that the region over which a particular cloud occurs is consistent from one year to another. The mean vertical distribution of all the cloud types over the ISM region is also established. The vertical structure of DC showed year-to-year variations, which is consistent with the India summer monsoon rainfall observations during that study period. It is envisaged that the present study will be helpful in quantifying the feedback of an individual cloud type to the ISM. Even though the present study discussed the prevailing dynamical features during the ISM period to some extent, further investigations are needed to look into the dynamical aspects associated with the ISM and their role in dictating the observed distribution of a particular cloud type, which will be our immediate priority.

Acknowledgements. The authors are greatly thankful to the CloudSat team for the 2B-CLDCLASS data, which were obtained from 
the CloudSat website http://www.cloudsat.cira.colostate.edu.

Topical Editor P. Drobinski thanks one anonymous referee for her/his help in evaluating this paper.

\section{References}

Behrangi, A., Casey, S. P. F., and Lambrigtsen, B. H.: Threedimensional distribution of cloud types over the USA and surrounding areas observed by CloudSat, Int. J. Remote Sens., 33, 4856-4870, 2012.

Chen, T., Rossow, W. B., and Zhang, Y.: Radiative effects of cloudtype variations, J. Climate, 13, 264-286, 2000.

Gadgil, S.: The Indian Monsoon and its variability, Annu. Rev. Earth Planet. Sci., 31, 429-467, 2003.

Goswami, B. N. and Xavier, P. K.: Dynamics of "internal" interannual variability of the Indian summer monsoon in a GCM, J. Geophys. Res., 110, D24104, doi:10.1029/2005JD006042, 2005.

Grossman, R. and Garcia, O.: The distribution of deep convection over ocean and land during the Asian summer monsoon, J. Climate, 3, 1032-1044, 1990.

Houze, R. A., Wilton, D. C., and Smull, B. F.: Monsoon convection in the Himalayan region as seen by the TRMM Precipitation Radar, Q. J. Roy. Meteorol. Soc., 133, 389-1411, 2007.

Laing, A. G. and Fritsch, J. M.: Mesoscale convective complexes over the Indian monsoon region, J. Climate, 6, 911-919, 1993.

Li, J., Yi, Y., Minnis, P., Huang, J., Yan, H., Ma, Y., Wang, W., J., and Ayers, K.: Radiative effect differences between multi-layered and single-layer clouds derived from CERES, CALIPSO, and CloudSat data, J. Quant. Spectr. Radiat. T., 112, 361-375, 2011.

Ramanathan, V., Cess, R. D., Harrison, E. F., Minnis, P., Barkstrom, B. R., Ahmad, E., and Hartmann, D.: Cloud-radiative forcing and climate: results from the earth radiation budget experiment, Science, 24, 357-363, 1989.

Rogers, M. and Vane, D.: The Cloudsat Education Network: Scientifically significant collaborative research between students and scientists," Geoscience and Remote Sensing Symposium (IGARSS), 2010 IEEE International, 84, 25-30, doi:10.1109/IGARSS.2010.5651427, 2010.
Sassen, K. and Wang, Z.: Classifying clouds around the globe with the CloudSat radar: 1- year of results,Geophys. Res. Lett., 35, L04805, doi:10.1029/2007GL032591, 2008.

Sathiyamoorthy, V., Pal, P. K., and Joshi, P. C.: Influence of the upper tropospheric wind shear upon cloud radiative forcing in the Asian monsoon region, J. Climate, 17, 2725-2735, 2004.

Sathiyamoorthy, V., Shukla, B. P., and Pal, P. K.: A study on radiative properties of Indian summer monsoon clouds, Meteorol. Atmos. Phys., 113, 55-66, 2011.

Stephens, G. L., Vane, D. G., Tanelli, S., Im, E., Durden, S., Rokey, M., Reinke, D., Partain, P., Mace, G. G., Austin, R., L'Ecuyer, T., Haynes, J., Lebsock, M., Suzuki, K., Waliser, D., Wu, D., Kay, J., Gettelman, A., Wang, Z., and Marchand, R.: CloudSat mission: Performance and early science after the first year of operation. J. Geophys. Res., 113, D00A18, doi:10.1029/2008JD009982, 2008.

Tang, X. and Chen, B.: Cloud type associated with the Asian summer monsoons as determined from MODIS/TERRA measurements and a comparison with surface observations, Geophys. Res. Lett., 33, L07814, doi:10.1029/2006GL026004, 2006.

Wallace, J. M. and Hobbs, P. V.: Atmospheric Science: An Introductory Survey, Academic Press: Orlando, FL, USA, 1977.

Wang, Z. and Sassen, K.: Cloud type and macrophysical property retrieval using multiple remote sensors, J. Appl. Meteorol., 40, 1665-1682, 2001.

Webster, P. J., Magaña,V. O., Palmer, T. N., Shukla, J., Tomas, R. A., Yanai, M., and Yasunari, T.: Monsoons: Processes, predictability, and the prospects for prediction, J. Geophys. Res., 103, 1445114510, 1998.

Wonsick, M. M., Pinker, R. T., and Govaerts, Y.: Cloud Variability over the Indian Monsoon Region as Observed from Satellites, J. Appl. Meteorol. Clim., 48, 1803-1821, 2009.

Zuidema, P.: Convective clouds over the Bay of Bengal, Mon. Weather Rev., 131, 780-798, 2003. 